Article

\title{
Health-Related Quality of Life in Levothyroxine-Treated Hypothyroid Women and Women without Hypothyroidism: A Case-Control Study
}

\author{
Benjamín Romero-Gómez ${ }^{1}$ (D), Paula Guerrero-Alonso ${ }^{2}$, Juan Manuel Carmona-Torres ${ }^{3,4,5}$ (D), \\ Diana P. Pozuelo-Carrascosa ${ }^{3,4}$ (D), José Alberto Laredo-Aguilera ${ }^{3,4,5, * \mathbb{D}}$ \\ and Ana Isabel Cobo-Cuenca ${ }^{3,4,5}$ (D) \\ 1 Hospital El Tomillar de Sevilla, Servicio Andaluz de Salud (SAS), 41500 Alcalá de Guadaira, Spain; \\ volvart@hotmail.com \\ 2 Centro de Salud Najera, Servicio Rioja Salud, 26300 Najera, Spain; pguerrero@riojasalud.es \\ 3 Facultad de Fisioterapia y Enfermería de Toledo, Universidad de Castilla la Mancha, 45005 Toledo, Spain; \\ juanmanuel.carmona@uclm.es (J.M.C.-T.); dianaP.Pozuelo@uclm.es (D.P.P.-C.); \\ anaisabel.cobo@uclm.es (A.I.C.-C.) \\ 4 Grupo de Investigación Multidisciplinar en Cuidados (IMCU), Universidad de Castilla la Mancha, \\ 45005 Toledo, Spain \\ 5 Instituto Maimónides de Investigación Biomédica de Córdoba (IMIBIC-GE08), 14004 Córdoba, Spain \\ * Correspondence: Josealberto.laredo@uclm.es
}

Received: 7 November 2020; Accepted: 26 November 2020; Published: 27 November 2020

\begin{abstract}
The use of levothyroxine is not always related to the elimination of the symptoms of hypothyroidism. The aim of this study is to compare the health-related quality of life (HRQOL) of a group of hypothyroid women under levothyroxine treatment with that of a group of non-hypothyroid women. Methodology: A case-control study was performed. We used convenience sampling. The case group consisted of 152 levothyroxine-treated hypothyroid women; the control group consisted of 238 women without hypothyroidism disorders. All of the participants were euthyroid according to the clinical practice guidelines. We used as instruments the Short Form-12 questionnaire (SF-12v1) and a sociodemographic questionnaire. Results: Hypothyroid women scored significantly lower in HRQOL in SF-12v1 mental and physical components than the control group (mental component summary: $41.23 \pm 12.12$ vs. $46.45 \pm 10.22, p<0.001$; physical component summary: $49.64 \pm 10.16$ vs. $54.75 \pm 5.76, p<0.001)$. body mass index (BMI) and age showed an influence on the physical component $(p<0.001$ in both variables). Adjusted for age and BMI, hypothyroidism was still related to worse scores $(p<0.001)$. Conclusion: Despite being euthyroid, women with hypothyroidism showed a poorer quality of life than women without hypothyroidism. Health professionals need to assess the HRQOL of women with hypothyroidism. Further research on HRQOL and hypothyroidism is needed.
\end{abstract}

Keywords: hypothyroidism; quality of life; health; women; thyroid hormone

\section{Introduction}

The thyroid gland plays an important role in the regulation of metabolism through the synthesis of two hormones-thyroxine (T4) and triiodothyronine (T3) [1]. These hormones have receptors in very different parts of the body, from peripheral tissues to brain structures [2,3]. This may explain why alterations in its secretion, either in excess or defect, can lead to diverse symptoms in the organism. 
Among thyroid disorders, hypothyroidism is the most common, especially in women [4]. Hypothyroidism is defined by insufficient hormone production by the thyroid gland. In response, hypophysis increases the levels of the thyroid-stimulating hormone (TSH) in order to stimulate the thyroid gland. This compensatory mechanism is effective for a while, although it may become insufficient. When it occurs, the disease is called overt hypothyroidism. In this new situation, patients show low serum levels of thyroid hormones and an increase in TSH serum levels [5]. Hypothyroidism is a disease with an insidious course, characterized by very subtle initial symptoms that hinder the diagnosis. It may cause very different disorders: tiredness, impaired cognition, anxiety disorders, depressive symptoms, decreased information processing speed, reduced efficiency of executive functions, poor learning, dry and coarse skin, muscle weakness, sexual dysfunction, constipation, and weight gain [6-11].

While hypothyroidism may have different etiologies, the most common treatment is the intake of levothyroxine sodium (LT4) after an overnight fast [12]. It allows the recovery of T4 hormone serum levels [13] and, indirectly, the normalization of TSH levels. TSH levels are usually considered the indicator of treatment efficacy. The treatment is considered appropriate when TSH levels return to their normal range (0.4-4.0 mIU/L) [12]. Besides being an effective, safe, and simple treatment [5], the use of levothyroxine clearly reduces symptoms for most of the patients [8,14-17].

Nonetheless, it has been observed in recent years that symptoms remain in some patients despite reaching euthyroidism [5,18]. For example, the persistency of tiredness complaints, cognitive dysfunction, sexual disorders, mood disorders, working memory disorders, and motor learning disorders in properly treated patients have been reported [11,19-22]. On the contrary, several authors found no more neuropsychological problems in treated hypothyroid patients than in controls [23-25]. Similarly, Engum et al. reported no unusual anxiety or depression disorders in patients with thyroid disorders treated with levothyroxine [26].

The effects of levothyroxine treatment on health-related quality of life (HRQOL) are under research. HRQOL is a wide concept that implies the subjective assessment of different facets of life and their relationship with well-being [27]. Two main measurement components are usually differentiated: the physical component summary (PCS) and the mental component summary (MCS) [28,29]. Similar to other chronic diseases, nontreated hypothyroidism reduces the HRQOL of patients [22,30]. Furthermore, it has been proven that levothyroxine treatment improves the HRQOL of these patients [22]. However, this improvement seems incomplete; several authors have suggested that mean scores in HRQOL are lower in treated patients than in the general population [19,31]. On the other hand, Rakhshan et al. does not report those differences in treated patients [32].

Faced with such contradictory data, the aim of this study is to compare the health-related quality of life (HRQOL) of a group of hypothyroid women under levothyroxine treatment with that of a group of non-hypothyroid women.

\section{Materials and Methods}

\subsection{Design and Study Population}

From October 2018 to March 2019, 390 adult women (18-64 years old) were recruited among the patients of two primary care health zones in Spain. All of them were euthyroid. Women were divided into two groups: (1) the case group: 152 women with primary hypothyroidism treated with levothyroxine; (2) the control group: 238 women without thyroid disorders.

Inclusion criteria for the case group were (1) previous medical diagnosis of primary hypothyroidism, (2) at least 6 months of levothyroxine treatment, with the same dose, (3) normalized TSH levels (0.4-4.0 mIU/L). Exclusion criteria were (1) diagnosis of secondary or subclinical hypothyroidism, (2) abnormal TSH levels, (3) being pregnant or lactating, (4) diagnosis of psychiatric disease, endocrine disorder, or serious disease (e.g., cancer, heart problems), or (5) consumption of medications that may interfere with thyroid function (e.g., chemotherapy). 
Inclusion criteria for the control group were (1) absence of thyroid disorders, and (2) euthyroidism (TSH levels 0.4-4.0 mIU/L). Exclusion criteria were (1) abnormal TSH levels, (2) being pregnant or lactating, (3) diagnosis of psychiatric disease, endocrine disorder, or serious disease (e.g., cancer, heart problems), and (4) consumption of medications that may interfere with thyroid function (e.g., chemotherapy).

\subsection{Sample Size}

Using the Short Form-12 questionnaire (SF-12v1), Vilagut et al. found a mean score for the physical component summary (PCS) of $52.13 \pm 8.28$ and for the mental component summary (MCS) of $50.58 \pm 9.13$ in Spanish women between 35 and 49 years old [33]. Based on these data, a sample of 59 women in each group was considered sufficient, with an $\alpha$ risk of 0.05 , a $\beta$ risk of 0.2 , a level of confidence of $95 \%$, and a replacement rate of $10 \%$. Sample size was calculated using Granmo software (version 7.12, Antaviana, Institut Municipal d’investigatio medica, Barcelona, Spain).

\subsection{Instruments}

An online questionnaire was constructed. It included two instruments to measure the variables.

(1) Questionnaire on sociodemographic variables (age, tobacco consumption, educational level, employment status, civil status, cohabitation, and sexual orientation). Clinical variables-BMI, etiology of hypothyroidism, and TSH levels-were collected during the patients' annual reviews.

(2) SF-12v1 [34,35]. It was designed to measure HRQOL. It assesses levels of well-being and functional capacity in people aged 14 or older in two dimensions: PCS and MCS. It comprises 12 items with Likert-type and dichotomous responses. Scores are transformed and normalized in order to obtain the final result [36]. The mean score in the Spanish population is established at $50 \pm 10$ [33]. This mean is a validated and reliable measure, with a Cronbach's alpha greater than 0.70 in both components [33].

\subsection{Data Collection}

Healthcare professionals from both primary care health zones were contacted and invited to participate in our study.

Convenience sampling was used. Subjects were recruited when they attended a scheduled visit to follow-up on their thyroid disease. They all had to be fluent in Spanish. Moreover, inclusion and exclusion criteria were reviewed. After giving their informed consent, their height, weight, and results of the blood tests were collected. All blood samples were taken at 8.00 a.m. after an 8 -h overnight fast. Only euthyroid women (TSH 0.4-4.0 mIU/L) were selected. Participants were not directly contacted by the researchers. Women who met all the criteria were provided with a link to the online questionnaire. This questionnaire was anonymous and did not collect any personal data other than the variables of this study.

\subsection{Study Variables}

\subsubsection{Independent Variables}

Sociodemographic variables: age (quantitative), educational level (categorical), employment status (categorical), sexual orientation (categorical), civil status (categorical), and cohabitation (dichotomous). Clinical variables: presence/absence of hypothyroidism (dichotomous), etiology of hypothyroidism (categorical), tobacco consumption (dichotomous), and BMI (quantitative/categorical).

\subsubsection{Dependent Variables}

The SF-12v1 questionnaire measures two different components: PCS and MCS. These variables were used as both quantitative and categorical variables. 


\subsection{Statistical Analysis}

A descriptive analysis of the variables was performed by calculating counts (n) and proportions (\%) of the qualitative variables and means $(\mathrm{m})$ and standard deviations (SD) of the quantitative variables. The Kolmogorov-Smirnov test was used to test for data normality. Quantitative data were analyzed by Student's t-test. A $\chi$-square test was used to analyze the categorical variables. Finally, a univariable logistic regression model and an analysis of covariance (ANCOVA) adjusted for age and BMI were performed. All hypotheses contrasts were bilateral, and a value of $p<0.05$ was considered significant in all tests. Data were analyzed using the statistical software IBM SPSS (version 22.0, IBM Corp, Armonk, NY, USA).

\subsection{Ethical Considerations}

This study follows the fundamental principles of the UNESCO Universal Declaration of Human Rights, the Helsinki Declaration, Spanish Organic Law 3/2018 of 5 December on the Protection of Personal Data and Guarantee of Digital Rights, keeping it strictly confidential and not accessible to unauthorized third parties, and Regulation (EU) 2016/679 of the European Parliament and Council of 27 April 2016 on Data Protection (RGPD) of the Spanish State. The study was approved by the institutional ethical committees from both primary care health zones (Comité de Ética del Complejo hospitalario de Toledo CEITO (273/18) and Comité de Ética e Investigación Provincial de Málaga CEIMA (25/2018)).

\section{Results}

\subsection{Clinical and Sociodemographic Variables}

A total of 390 women met the participation criteria and completed the online questionnaires. The case group included $152(39.97 \%)$ of these women. Mean BMI was $23.54 \pm 4.09$, and mean age, $35.49 \pm 9.41$. The most common etiology of hypothyroidism was autoimmune $(n=134,88.2 \%)$. Mean TSH level was $2.22 \pm 0.90$. In the total sample, $97(24.9 \%)$ women were habitual smokers. There were 292 (74.9\%) women with university studies; 285 (73.05\%) women were employed. Regarding sexual relations, 349 (89.5\%) women were heterosexual, 307 (78.7\%) were married or had a steady partner, and $232(59.5 \%)$ were cohabitating (Table 1$)$.

Table 1. Sociodemographic and clinical variables.

\begin{tabular}{|c|c|c|c|c|}
\hline Variable & Case Group & Control Group & Total & $p$ \\
\hline & $n=152$ & $n=238$ & $n=390$ & \\
\hline & Mean (SD) & Mean (SD) & Mean (SD) & $t$-test \\
\hline Age & $36.58(9.96)$ & $34.79(8.99)$ & $35.49(9.41)$ & 0.068 \\
\hline \multirow[t]{2}{*}{ BMI } & $24.41(4.59)$ & $22.99(3.65)$ & $23.54(4.09)$ & 0.001 \\
\hline & $n(\%)$ & $n(\%)$ & $n(\%)$ & $x^{2}$ \\
\hline \multicolumn{5}{|c|}{ Etiology of hypothyroidism } \\
\hline Autoimmune & $134(88.2 \%)$ & - & - & - \\
\hline Others & $18(11.8 \%)$ & - & - & - \\
\hline \multicolumn{5}{|c|}{ Tobacco consumption } \\
\hline Yes & $40(26.3 \%)$ & $57(23.9 \%)$ & $97(24.9 \%)$ & 0.598 \\
\hline No & $112(73.7 \%)$ & $181(76.1 \%)$ & $293(75.1 \%)$ & \\
\hline \multicolumn{5}{|c|}{ Civil status } \\
\hline Single & $24(15.8 \%)$ & $34(14.3 \%)$ & $58(14.9 \%)$ & 0.910 \\
\hline Married/steady & $118(77.6 \%)$ & $189(79.4 \%)$ & $307(78.7 \%)$ & \\
\hline Other & $10(6.6 \%)$ & $15(6.3 \%)$ & $256.4 \%)$ & \\
\hline
\end{tabular}


Table 1. Cont.

\begin{tabular}{ccccc}
\hline Variable & Case Group & Control Group & Total & $p$ \\
\hline Lesbian & $6(6.95 \%)$ & Sexual orientation & \\
Heterosexual & $135(88.82 \%)$ & $214(89.95 \%)$ & $14(3.6 \%)$ & 0.934 \\
Bisexual & $11(7.23 \%)$ & $16(6.7 \%)$ & $27(6.9 \%)$ & \\
\hline \multicolumn{5}{c}{ Cohabitation } \\
Yes & $101(66.5 \%)$ & $131(55 \%)$ & $232(59.5 \%)$ & 0.025 \\
No & $51(33.5 \%)$ & $107(45 \%)$ & $158(40.5 \%)$ & \\
Primary & $15(9.85 \%)$ & Educational level & \\
Secondary & $39(25.65 \%)$ & $38(15.95 \%)$ & $77(19.7 \%)$ & \\
University & $98(64.5 \%)$ & $194(81.55 \%)$ & $292(74.9 \%)$ & \\
\hline \multicolumn{5}{c}{ Employment status } \\
Student & $16(10.5 \%)$ & $31(13 \%)$ & $47(12.05 \%)$ & 0.001 \\
Employed & $101(66.5 \%)$ & $184(77.3 \%)$ & $285(73.05 \%)$ & \\
Other & $35(23 \%)$ & $23(9.7 \%)$ & $58(14.9 \%)$ & \\
\hline
\end{tabular}

SD: standard deviation.

Both groups were compared using Student's $t$-test (quantitative) and a $\chi$-square test (categorical) (Table 1).

\subsection{SF-12v1 Results}

Mean scores in the case group were significantly lower than in the control group in both summary components $(p<0.001$; Table 2$)$.

Table 2. HRQOL scores in the case group (women with hypothyroidism) and the control group (women without hypothyroidism).

\begin{tabular}{|c|c|c|c|c|}
\hline Variable & Case Group & Control Group & Total & $p$ \\
\hline & $n=152$ & $n=238$ & $n=390$ & $t$-test \\
\hline PCS & $49.64(10.16)$ & $54.75(5.76)$ & $52.76(8.15)$ & $p<0.001$ \\
\hline MCS & $41.23(12.12)$ & $46.45(10.22)$ & $44.41(11.27)$ & $p<0.001$ \\
\hline \multicolumn{2}{|c|}{ PCS total score } & & & x-square \\
\hline$<50$ & $60(39.5 \%)$ & $40(17 \%)$ & $100(25.5 \%)$ & $n<0.001$ \\
\hline$>50$ & $92(60.5 \%)$ & $198(83 \%)$ & $290(74.5 \%)$ & $p<0.001$ \\
\hline \multicolumn{4}{|c|}{ MCS total score } & \multirow{3}{*}{$p<0.001$} \\
\hline$<50$ & $103(67.75 \%)$ & $118(49.5 \%)$ & $221(56.5 \%)$ & \\
\hline$>50$ & $49(22.25 \%)$ & $120(50.5 \%)$ & $169(43.5 \%)$ & \\
\hline
\end{tabular}

SF-12v1 scores were dichotomized based on the Spanish mean $(50 \pm 10)$. Scores below 50 in any of the components show a quality of life lower than the mean; scores above 50 show a quality of life higher than the mean.

In the case group, 39.5\% of women scored below the Spanish mean in the PCS (17\% in the control group) and $67.75 \%$ of them in the MCS (49.5\% in the control group). These differences were also significant in both components ( $p<0.001$; Table 2$)$.

Logistic regression was used in order to assess the effect of the independent variables on HRQOL. The variable HRQOL was dichotomized $(>50,<50)$. Regarding the MCS, only hypothyroidism showed a significant influence on HRQOL ( $p=0.020$, OR: $1.98(1.11-3.52)$ ). Regarding the PCS, a significant influence of BMI $(p=0.008)$ and age $(p=0.032)$ on the total sample and of age $(p=0.001)$ in hypothyroid 
women (Table 3) was found. All other variables (e.g., etiology, tobacco consumption, civil status) were not significant.

Table 3. Relationship between independent variables and PCS *.

\begin{tabular}{ccccccc}
\hline Variables & \multicolumn{2}{c}{ Case Group } & \multicolumn{2}{c}{ Control Group } & \multicolumn{2}{c}{ Total Women } \\
\hline & $p$ & OR (CI 95\%) & $p$ & OR (CI 95\%) & $p$ & OR (CI 95\%) \\
\hline Hypothyroidism & - & - & - & - & 0.001 & $2.76(1.47-5.15)$ \\
\hline BMI & 0.055 & $0.92(0.84-1.00)$ & 0.061 & $0.91(0.83-1.00)$ & 0.008 & $0.92(0.86-0.97)$ \\
\hline Age & 0.001 & $0.91(0.87-0.96)$ & 0.801 & $1.00(0.95-1.05)$ & 0.032 & $0.96(0.93-0.99)$ \\
\hline \multicolumn{2}{c}{ * Only significant results are shown. BMI: body mass index; OR: odds ratio; CI: confidence interval. }
\end{tabular}

Hypothyroidism increased the risk of a lower HRQOL $(<50)$ in the MCS $(p=0.020$, OR: 1.98 (1.11-3.52)) and in the PCS ( $p=0.001$, OR: 2.76 (1.47-5.15); Tables 3 and 4).

Table 4. Mean differences (analysis of covariance (ANCOVA)) in the mental component summary adjusted for age (Model 0 ) and adjusted for age + BMI (Model 1).

\begin{tabular}{ccccccc}
\hline Variables & \multicolumn{2}{c}{ Case Group } & \multicolumn{2}{c}{ Control Group } & F-test & $p$ \\
\hline Model 0 & M (SD) & CI adjusted & M (SD) & CI adjusted & & \\
\hline PCS & $49.82(0.62)$ & $48.59-51.04$ & $54.64(0.49)$ & $53.66-55.62$ & 36.56 & $p<0.001$ \\
\hline Model 1 & M (SD) & CI adjusted & M (SD) & CI adjusted & & \\
\hline PCS & $50.07(0.61)$ & $48.86-51.29$ & $54.48(0.49)$ & $53.51-55.44$ & 30.57 & $p<0.001$ \\
\hline
\end{tabular}

M: marginal estimated means \pm SD. Model 0: adjusted for age. Model 1: adjusted for age + BMI. Statistical significance $(p<0.05)$ in pairwise mean comparisons using the Bonferroni posthoc test; BMI, body mass index; SD: standard deviation; CI, confidence interval., PCS, physical component summary.

The specific influence of hypothyroidism on the PCS was evaluated using an analysis of covariance (ANCOVA), adjusted for "Age" (Model 0) and "Age and BMI" (Model 1) variables. Hypothyroidism remained significant $(p<0.001)$ in both models (Table 4$)$.

\section{Discussion}

HRQOL is a construct widely used in current research to measure subjective well-being. This measurement can be influenced by different sociodemographic aspects such as age, health behavior, physical or mental disease, and productivity [37].

In our study, we found that hypothyroid women under LT4 treatment showed significantly lower scores in SF-12v1 physical and mental components than the general Spanish population [33]. Moreover, the proportion of women with HRQOL scores below the Spanish mean was significantly higher in hypothyroid women in both components. These differences could not be explained by other sociodemographic factors (e.g., educational level, etiology, civil status). Age and BMI affected the quality of life; however, after isolating the effect of both factors, hypothyroidism still showed a significant influence on HRQOL. In this sense, our results coincide with those of Djurovic et al. [38], who observed impairment in general well-being in patients with Hashimoto's thyroiditis.

Regarding age, Djurovic et al. found significant differences when patients were older than 50 years but not when they were younger than 50 years [38]. However, in our study, hypothyroidism still showed an influence on HRQOL, independent of age. Winther et al. also reported that although HRQOL improved with treatment, it was still worse than in controls after six months of treatment [22]. Unlike our study, they found significant differences only in the SF-36 mental component and not in the physical one [22]. Given that their sample was of older age, physical problems associated with hypothyroidism could resemble those of aging and, therefore, become less evident. 
Saravanan et al. reported lower mental well-being in hypothyroid patients despite treatment. Saravanan used a large sample, although, according to the author, with a high proportion of chronic diseases [39]. As noted before, these diseases may hide symptoms of hypothyroidism.

Our data show that HRQOL in levothyroxine-treated hypothyroid women is worse than in controls. Other studies also found a worse HRQOL in hypothyroid patients $[19,40,41]$, although they used reference values for the general population instead of control groups. On the other hand, with a smaller sample, Rakhshan et al. observed no difference in the quality of life between patients with hypothyroidism and a healthy population [32]; however, they reported lower scores in mental health. None of the mentioned studies was sex-specific-all included men in their samples [19,22,32,38-41]. Therefore, there could be differences between sexes that may explain the differences with our results.

Age and BMI showed an influence on HRQOL in the physical component summary. Aging is related to changes in couple relationships, physical appearance, or sexuality, as well as to climacteric symptoms [42]. On the one hand, climacteric and menopause trigger a decline in the quality of life in women $[43,44]$; on the other hand, a previous study reported that hypothyroid women showed a higher prevalence of sexual disorder than non-hypothyroid women [11]. It is noteworthy that the mean age of our sample was lower than in other studies about HRQOL and hypothyroidism [31,38,41,45].

Hypothyroid women usually gain more weight than the general population, even after reaching euthyroidism [46]. In our study, women with hypothyroidism had a higher BMI than control women $(24.41 \pm 4.59$ vs. $22.99 \pm 3.65)$. The increase in BMI in treated hypothyroid women has also been reported by other studies [40,47]. However, Singh et al. and Massolt et al. found no differences in the BMI values, although Singh did not have a control group [17,45]. Overweight has been generally associated with a decrease in HRQOL [48]. It also has been related to several health problems, such as hypertension, diabetes, or cardiovascular diseases [49]. In a study with hypothyroid patients under treatment, the authors reported that the increase in BMI was related to decreased QOL [40]. Nonetheless, Michaelsson et al. found no relationship between BMI and quality of life [31].

Hypothyroid patients tend to complain about weight gain due to the disease. These complaints refer to unsatisfactory weight gain after starting the treatment as well as to its impact on psychological well-being and body image, especially in women [39].

In our study, the effects of age and BMI were adjusted through ANCOVA, and it was found that hypothyroidism still showed a significant influence on HRQOL. Therefore, the differences in HRQOL could be explained by the hypothyroidism itself.

HRQOL may be affected by social, economic, and cultural aspects [37]. Although in our study, different variables were assessed, such as tobacco consumption, educational level, employment status, sexual orientation, civil status, or cohabitation, we found no relation with HRQOL in hypothyroid women. In line with Morón et al. [41], our results showed no relation between HRQOL and tobacco consumption, living arrangement, or educational level. Rakhshan et al. observed a significant relationship between educational level and mental health, but it disappeared when assessing its relationship with quality of life. This author reported no changes in QOL regarding marital status or job status [32]. Regarding etiology, it has been suggested that an autoimmune origin could affect HRQOL [18]. In our study, etiology showed no significant effect on HRQOL.

As previously stated, LT4 allows hypothyroid patients to reach euthyroidism. Nevertheless, this seems insufficient to resolve the symptoms in all the patients. Although its causes are not fully known, different explanations have been proposed. Firstly, the probability of a genetic susceptibility due to the presence of polymorphisms of the type 2 deiodinase enzyme, responsible for the conversion of T4 to T3 in different tissues, has been postulated [12,50]. These alterations could affect the enzyme function and, thus, be related to the persistence of symptoms [12,50-52]. Furthermore, it has been suggested that monotherapy with LT4 may not be sufficient to resolve the symptoms of hypothyroidism since it does not replicate the normal physiology of thyroid hormones [18]. Although $80 \%$ of T3 is obtained by transforming T4 in T3 through the action of deiodinases, the remaining $20 \%$ is directly 
synthetized by the thyroid gland. The T3 released by the thyroid gland could conduct some direct physiological action [18].

It has also been considered that TSH levels may not be the most appropriate marker to assess euthyroidism. Treated patients with normalized TSH levels have been found to have higher levels of T4 and fT4 than controls, higher T4/T3 or FT4/FT3 ratios [53-55], and lower serum T3 and FT3 concentrations [47]. Another alternative treatment to LT4 monotherapy is the use of desiccated thyroid extracts (DET). Peterson et al. reported that patients treated with DET showed higher satisfaction with their treatments than patients treated only with LT4. The use of DET causes supraphysiologic T3 serum levels, which may improve mood in patients with depressive symptoms. On the other hand, higher satisfaction could be due to other unknown mechanisms related to thyroid metabolism [56]. In the same way, Mitchell et al. observed that patients treated with DET or an LT3/LT4 combination showed better QOL than patients with LT4 monotherapy. Nevertheless, these differences disappeared when introducing other elements in the analysis (prior healthcare experiences and expectations on treatment) [57]. This study suggested that improving the patient experience and clarifying expectations at diagnosis could improve satisfaction and quality of life [57]. Several studies have researched the effect of the LT3/LT4 combination instead of LT4 monotherapy; however, although some patients prefer the LT3/LT4 combination, the evidence does not conclusively show a clear benefit of this combined therapy $[5,18]$.

Lastly, the influence of other psychological and physical factors has also been considered. Among physical factors, besides the possible influence of BMI, hypothyroidism may be related to the presence of chronic diseases whose symptoms may overlap [18]. In our sample, women had no other severe chronic diseases. Regarding psychological factors, a possible bias related to chronic diseases due to the worse perception of health by these patients must be considered. This effect has been observed in patients with hypertension or diabetes [58]. A higher prevalence of anxiety and depression disorders in these patients has also been reported [50,59], although this might be a consequence rather than a cause of these problems.

\section{Strengths and Limitations}

Among the strengths of this study, the size of its sample is noteworthy as it is larger than in similar previous studies. Moreover, since it was focused on women, the possible presence of gender bias is reduced. To the best of our knowledge, this is the first study comparing HRQOL among hypothyroid women treated with levothyroxine and controls in the Spanish population. On the other hand, this study is not free from limitations. First, as it is a case-control study, it is not possible to establish causal relationships. Second, responses to self-completed questionnaires may be influenced by social desirability.

\section{Conclusions}

Hypothyroid women under levothyroxine treatment showed lower scores in HRQOL than non-hypothyroid women. These differences were significant and could not be explained by any other variable in the study. These lower scores remained even after reaching euthyroidism. Increase in age and BMI were associated with a decrease in the physical component of quality of life, but not in the mental component. An intervention at different levels-assessing the expectations of the treatment, providing complete and appropriate information, nonpharmacological interventions, and research on new treatments—could help improve the HRQOL of these patients.

\section{Contributions of This Study}

To the best of our knowledge, this is the first study comparing HRQOL among hypothyroid women treated with levothyroxine and controls in the Spanish population. 
This study shows that although women with hypothyroidism under levothyroxine treatment may have normalized TSH levels, they still report a low quality of life. More studies of this type are needed, as healthcare providers should be aware of the impact of thyroid disorders on patients' lives.

Author Contributions: Conceptualization, B.R.-G. and A.I.C.-C.; methodology, B.R.-G. and A.I.C.-C.; software, B.R.-G. and A.I.C.-C.; validation, B.R.-G., J.M.C.-T., and A.I.C.-C.; formal analysis, B.R.-G. and A.I.C.-C.; data curation, B.R.-G., P.G.-A., and A.I.C.-C.; writing-original draft preparation, B.R.-G., and A.I.C.-C.; writing-review and editing, B.R.-G., P.G.-A., J.M.C.-T., J.A.L.-A., D.P.P-C., and A.I.C.-C.; visualization, B.R.-G., P.G.-A., J.M.C.-T., J.A.L.-A., D.P.P.-C., and A.I.C.-C.; supervision, A.I.C.-C.; project administration, A.I.C.-C. All authors have read and agreed to the published version of the manuscript.

Funding: This research was funded by a grant from the European Regional Development Fund (ERDF; Fondo Europeo de Desarrollo Regional (FEDER), DOCM 26/02/20).

Conflicts of Interest: The authors declare no conflict of interest.

\section{References}

1. Grimm, D. Cell and molecular biology of thyroid disorders. Int. J. Mol. Sci. 2019, 20, 2895. [CrossRef]

2. Funkquist, A.; Bengtsson, A.; Johansson, P.; Svensson, J.; Bjellerup, P.; Blennow, K.; Wandt, B.; Sjöberg, S. Low CSF/serum ratio of free T4 is associated with decreased quality of life in mild hypothyroidism-A pilot study. J. Clin. Transl. Endocrinol. 2020, 19, 100218. [CrossRef]

3. Parle, J.; Roberts, L.; Wilson, S.; Pattison, H.; Roalfe, A.; Haque, M.S.; Heath, C.; Sheppard, M.; Franklyn, J.; Hobbs, F.D.R. A randomized controlled trial of the effect of thyroxine replacement on cognitive function in community-living elderly subjects with subclinical hypothyroidism: The Birmingham Elderly Thyroid study. J. Clin. Endocrinol. Metab. 2010, 95, 3623-3632. [CrossRef]

4. Escribano-Serrano, J.; Mancera-Romero, J.; Santos-Sánchez, V.; Payá-Giner, C.; Méndez-Esteban, M.I.; García-Bonilla, A.; Márquez-Ferrando, M.; Hormigo-Pozo, A.; Michán-Doña, A. Prevalence of hypothyroidism in Andalusia, Spain, determined by thyroid hormone consumption. Rev. Esp. Salud Publica 2016, 90, e1-e12.

5. Okosieme, O.; Gilbert, J.; Abraham, P.; Boelaert, K.; Dayan, C.M.; Gurnell, M.; Leese, G.; McCabe, C.; Perros, P.; Smith, V.; et al. Management of primary hypothyroidism: Statement by the British Thyroid Association Executive Committee. Clin. Endocrinol. 2016, 84, 799-808. [CrossRef]

6. Bilous, I.I.; Korda, M.M.; Krynytska, I.Y.; Kamyshnyi, A.M. Nerve impulse transmission pathway-focused genes expression analysis in patients with primary hypothyroidism and autoimmune thyroiditis. Endocr. Regul. 2020, 54, 109-118. [CrossRef] [PubMed]

7. Chaker, L.; Bianco, A.C.; Jonklaas, J.; Peeters, R.P. Hypothyroidism. Lancet 2017, 390, 1550-1562. [CrossRef]

8. Gabrielson, A.T.; Sartor, R.A.; Hellstrom, W.J.G. The impact of thyroid disease on sexual dysfunction in men and women. Sex. Med. Rev. 2019, 7, 57-70. [CrossRef]

9. Ritchie, M.; Yeap, B.B. Thyroid hormone: Influences on mood and cognition in adults. Maturitas 2015, 81, 266-275. [CrossRef]

10. Romero-Gómez, B.; Guerrero-Alonso, P.; Carmona-Torres, J.M.; Notario-Pacheco, B.; Cobo-Cuenca, A.I. Mood disorders in levothyroxine-treated hypothyroid women. Int. J. Environ. Res. Public Health 2019, 16, 4776. [CrossRef]

11. Romero-Gómez, B.; Guerrero-Alonso, P.; Carmona-Torres, J.M.; Laredo-Aguilera, J.A.; Pozuelo-Carrascosa, D.P.; Cobo-Cuenca, A.I. Sexual function in levothyroxine-treated hypothyroid women and women without hypothyroidism: A case-control. Int. J. Environ. Res. Public Health 2020, 17, 4325. [CrossRef] [PubMed]

12. Jonklaas, J.; Bianco, A.C.; Bauer, A.J.; Burman, K.D.; Cappola, A.R.; Celi, F.S.; Cooper, D.S.; Kim, B.W.; Peeters, R.P.; Rosenthal, M.S.; et al. Guidelines for the treatment of hypothyroidism: Prepared by the American thyroid association task force on thyroid hormone replacement. Thyroid 2014, 24, 1670-1751. [CrossRef] [PubMed]

13. Bianco, A.C.; Salvatore, D.; Gereben, B.; Berry, M.J.; Larsen, P.R. Biochemistry, cellular and molecular biology, and physiological roles of the iodothyronine selenodeiodinases. Endocr. Rev. 2002, 23, 38-89. [CrossRef]

14. Correia, N.; Mullally, S.; Cooke, G.; Tun, T.K.; Phelan, N.; Feeney, J.; FitzGibbon, M.; Boran, G.; O’Mara, S.; Gibney, J. Evidence for a specific defect in hippocampal memory in overt and subclinical hypothyroidism. J. Clin. Endocrinol. Metab. 2009, 94, 3789-3797. [CrossRef] [PubMed] 
15. Gulseren, S.; Gulseren, L.; Hekimsoy, Z.; Cetinay, P.; Ozen, C.; Tokatlioglu, B. Depression, anxiety, health-related quality of life, and disability in patients with overt and subclinical thyroid dysfunction. Arch. Med. Res. 2006, 37, 133-139. [CrossRef] [PubMed]

16. Schraml, F.V.; Goslar, P.W.; Baxter, L.; Beason-Held, L.L. Thyroid stimulating hormone and cognition during severe, transient hypothyroidism. Neuro Endocrinol. Lett. 2011, 32, 279-285. [PubMed]

17. Singh, R.; Tandon, A.; Gupta, S.K.; Saroja, K. Optimal levothyroxine replacement adequately improves symptoms of hypothyroidism; residual symptoms need further evaluation for other than hypothyroidism causation. Indian J. Endocrinol. Metab. 2017, 21, 830-835.

18. Jonklaas, J. Persistent hypothyroid symptoms in a patient with a normal thyroid stimulating hormone level. Curr. Opin. Endocrinol. Diabetes Obes. 2017, 24, 356-363. [CrossRef]

19. Wekking, E.M.; Appelhof, B.C.; Fliers, E.; Schene, A.H.; Huyser, J.; Tijssen, J.G.P.; Wiersinga, W.M.; Gram, D.X.; Hansen, A.J.; Wilken, M.; et al. Cognitive functioning and well-being in euthyroid patients on thyroxine replacement therapy for primary hypothyroidism. Eur. J. Endocrinol. 2005, 153, 747-753. [CrossRef]

20. Samuels, M.H.; Schuff, K.G.; Carlson, N.E.; Carello, P.; Janowsky, J.S. Health status, psychological symptoms, mood, and cognition in L-thyroxine-treated hypothyroid subjects. Thyroid 2007, 17, 249-258. [CrossRef]

21. Quinque, E.M.; Villringer, A.; Kratzsch, J.; Karger, S. Patient-reported outcomes in adequately treated hypothyroidism-insights from the German versions of ThyDQoL, ThySRQ and ThyTSQ. Health Qual. Life Outcomes 2013, 11, 68. [CrossRef] [PubMed]

22. Winther, K.H.; Cramon, P.; Watt, T.; Bjorner, J.B.; Ekholm, O.; Feldt-Rasmussen, U.; Groenvold, M.; Rasmussen, Å.K.; Hegedüs, L.; Bonnema, S.J. Disease-specific as well as generic quality of life is widely impacted in autoimmune hypothyroidism and improves during the first six months of levothyroxine therapy. PLoS ONE 2016, 11, e0156925. [CrossRef] [PubMed]

23. Giannouli, V.; Toulis, K.A.; Syrmos, N. Cognitive function in Hashimoto's thyroiditis under levothyroxine treatment. Hormones (Athens) 2014, 13, 430-433. [CrossRef] [PubMed]

24. Giannouli, V.; Syrmos, N. A 2-year preliminary longitudinal study of neuropsychological functioning in Hashimoto's thyroiditis under levothyroxine treatment: Only Trail Making Test is making a difference. Probl. Psychol. 21st Century 2017, 11, 15-21.

25. Parsaik, A.K.; Singh, B.; Roberts, R.O.; Pankratz, S.; Edwards, K.K.; Geda, Y.E.; Gharib, H.; Boeve, B.F.; Knopman, D.S.; Petersen, R.C. Hypothyroidism and risk of mild cognitive impairment in elderly persons: A population-based study. JAMA Neurol. 2014, 71, 201-207. [CrossRef] [PubMed]

26. Engum, A.; Bjoro, T.; Mykletun, A.; Dahl, A.A. Thyroid autoimmunity, depression and anxiety; Are there any connections? An epidemiological study of a large population. J. Psychosom. Res. 2005, 59, $263-268$. [CrossRef]

27. Barofsky, I. Quality: Its Definition and Measurement as Applied to the Medically Ill; Springer: New York, NY, USA, 2012.

28. Stewart, A.L.; Hays, R.D.; Wells, K.B.; Rogers, W.H.; Spritzer, K.L.; Greenfield, S. Long-term functioning and well-being outcomes associated with physical activity and exercise in patients with chronic conditions in the Medical Outcomes Study. J. Clin. Epidemiol. 1994, 47, 719-730. [CrossRef]

29. Ware, J. Conceptualization and measurement of health-related quality of life: Comments on an evolving field. Arch. Phys. Med. Rehabil. 2003, 84, S43-S51. [CrossRef]

30. Bianchi, G.; Zaccheroni, V.; Solaroli, E.; Vescini, F.; Cerutti, R.; Zoli, M.; Marchesini, G. Health-related quality of life in patients with thyroid disorders. Qual. Life Res. 2004, 13, 45-54. [CrossRef]

31. Michaelsson, L.F.; La Cour, J.L.; Medici, B.B.; Watt, T.; Faber, J.; Nygaard, B. Levothyroxine/liothyronine combination therapy and quality of life: Is it all about weight loss? Eur. Thyroid. J. 2018, 7, $243-250$. [CrossRef]

32. Rakhshan, M.; Ghanbari, A.; Rahimi, A.; Mostafavi, I. A comparison between the quality of life and mental health of patients with hypothyroidism and normal people referred to Motahari Clinic of Shiraz University of Medical Sciences. Int. J. Community Based Nurs. Midwifery 2017, 5, 30-37.

33. Vilagut, G.; Valderas, J.M.; Ferrer, M.; Garin, O.; López-García, E.; Alonso, J. Interpretation of SF-36 and SF-12 questionnaires in Spain: Physical and mental components. Med. Clin. 2008, 130, 726-735. [CrossRef] [PubMed]

34. Ware, J.; Kosinski, M.; Keller, S.D. A 12-Item Short-Form Health Survey: Construction of scales and preliminary tests of reliability and validity. Med. Care 1996, 34, 220-233. [CrossRef] [PubMed] 
35. Gandek, B.; Ware, J.E.; Aaronson, N.K.; Apolone, G.; Bjorner, J.B.; Brazier, J.E.; Bullinger, M.; Kaasa, S.; Leplege, A.; Prieto, L.; et al. Cross-validation of item selection and scoring for the SF-12 Health Survey in nine countries: Results from the IQOLA Project. International Quality of Life Assessment. J. Clin. Epidemiol. 1998, 51, 1171-1178. [CrossRef]

36. Ware, J.E.; Kosinski, M.; Keller, S.D. SF-12: How to Score the SF-12 Physical and Mental Health Summary Scales, 2nd ed.; The Health Institute. New England Medical Center: Boston, MA, USA, 1995.

37. U.S. Department of Health and Human Services FDA Center for Drug Evaluation and Research; U.S. Department of Health and Human Services FDA Center for Biologics Evaluation and Research; U.S. Department of Health and Human Services FDA Center for Devices and Radiological Health. Guidance for industry: Patient-reported outcome measures: Use in medical product development to support labeling claims: Draft guidance. Health Qual. Life Outcomes 2006, 4, 79. [CrossRef] [PubMed]

38. Djurovic, M.; Pereira, A.M.; Smit, J.W.A.; Vasovic, O.; Damjanovic, S.; Jemuovic, Z.; Pavlovic, D.; Miljic, D.; Pekic, S.; Stojanovic, M.; et al. Cognitive functioning and quality of life in patients with Hashimoto thyroiditis on long-term levothyroxine replacement. Endocrine 2018, 62, 136-143. [CrossRef]

39. Saravanan, P.; Chau, W.F.; Roberts, N.; Vedhara, K.; Greenwood, R.; Dayan, C.M. Psychological well-being in patients on 'adequate' doses of L-thyroxine: Results of a large, controlled community-based questionnaire study. Clin. Endocrinol. 2002, 57, 577-585. [CrossRef]

40. Kelderman-Bolk, N.; Visser, T.J.; Tijssen, J.P.; Berghout, A. Quality of life in patients with primary hypothyroidism related to BMI. Eur. J. Endocrinol. 2015, 173, 507-515. [CrossRef]

41. Morón-Díaz, M.; Saavedra, P.; Alberiche-Ruano, M.P.; Rodríguez-Pérez, C.A.; López-Plasencia, Y.; Marrero-Arencibia, D.; González-Lleó, A.M.; Boronat, M. Correlation between TSH levels and quality of life among subjects with well-controlled primary hypothyroidism. Endocrine 2020. [CrossRef]

42. Chang, S.R.; Yang, C.F.; Chen, K.H. Relationships between body image, sexual dysfunction, and health-related quality of life among middle-aged women: A cross-sectional study. Maturitas 2019, 126, 45-50. [CrossRef]

43. Karaçam, Z.; Seker, S.E. Factors associated with menopausal symptoms and their relationship with the quality of life among Turkish women. Maturitas 2007, 58, 75-82. [CrossRef]

44. Bień, A.; Rzońca, E.; Iwanowicz-Palus, G.; Pańczyk-Szeptuch, M. The influence of climacteric symptoms on women's lives and activities. Int. J. Environ. Res. Public Health 2015, 12, 3835-3846. [CrossRef] [PubMed]

45. Massolt, E.T.; Van Der Windt, M.; Korevaar, T.; Kam, B.; Burger, J.; Franssen, G.; Lehmphul, I.; Köhrle, J.; Visser, W.E.; Peeters, R. Thyroid hormone and its metabolites in relation to quality of life in patients treated for differentiated thyroid cancer. Clin. Endocrinol. 2016, 85, 781-788. [CrossRef] [PubMed]

46. Jonklaas, J.; Nsouli-Maktabi, H. Weight changes in euthyroid patients undergoing thyroidectomy. Thyroid 2011, 21, 1343-1351. [CrossRef]

47. Peterson, S.J.; McAninch, E.A.; Bianco, A.C. Is a normal TSH synonymous with "euthyroidism" in levothyroxine monotherapy? J. Clin. Endocrinol. Metab. 2016, 101, 4964-4973. [CrossRef] [PubMed]

48. Katz, D.A.; McHorney, C.A.; Atkinson, R.L. Impact of obesity on health-related quality of life in patients with chronic illness. J. Gen. Intern. Med. 2000, 15, 789-796. [CrossRef] [PubMed]

49. Guh, D.P.; Zhang, W.; Bansback, N.; Amarsi, Z.; Birmingham, C.L.; Anis, A.H. The incidence of co-morbidities related to obesity and overweight: A systematic review and meta-analysis. BMC Public Health 2009, 9, 88. [CrossRef]

50. Wouters, H.J.C.M.; Van Loon, H.C.M.; Van Der Klauw, M.M.; Elderson, M.F.; Slagter, S.N.; Kobold, A.M.; Kema, I.P.; Links, T.P.; Van Vliet-Ostaptchouk, J.V.; Wolffenbuttel, B.H.R. No effect of the Thr92Ala polymorphism of deiodinase- 2 on thyroid hormone parameters, health-related quality of life, and cognitive functioning in a large population-based cohort study. Thyroid 2017, 27, 147-155. [CrossRef]

51. Panicker, V.; Evans, J.; Bjøro, T.; Asvold, B.O.; Dayan, C.M.; Bjerkeset, O. A paradoxical difference in relationship between anxiety, depression and thyroid function in subjects on and not on T4: Findings from the HUNT study. Clin. Endocrinol. 2009, 71, 574-580. [CrossRef]

52. McAninch, E.A.; Jo, S.; Preite, N.Z.; Farkas, E.; Mohácsik, P.; Fekete, C.; Egri, P.; Gereben, B.; Li, Y.; Deng, Y.; et al. Prevalent polymorphism in thyroid hormone-activating enzyme leaves a genetic fingerprint that underlies associated clinical syndromes. J. Clin. Endocrinol. Metab. 2015, 100, 920-933. [CrossRef]

53. Alevizaki, M.; Mantzou, E.; Cimponeriu, A.T.; Alevizaki, C.C.; Koutras, D.A. TSH may not be a good marker for adequate thyroid hormone replacement therapy. Wien Klin. Wochenschr. 2005, 117, 636-640. [CrossRef] [PubMed] 
54. Gullo, D.; Latina, A.; Frasca, F.; Le Moli, R.; Pellegriti, G.; Vigneri, R. Levothyroxine monotherapy cannot guarantee euthyroidism in all athyreotic patients. PLOS ONE 2011, 6, e22552. [CrossRef] [PubMed]

55. Jonklaas, J.; Davidson, B.; Bhagat, S.; Soldin, S.J. Triiodothyronine levels in athyreotic individuals during levothyroxine therapy. JAMA 2008, 299, 769-777. [CrossRef] [PubMed]

56. Peterson, S.J.; Cappola, A.R.; Castro, M.R.; Dayan, C.M.; Farwell, A.P.; Hennessey, J.V.; Kopp, P.; Ross, D.S.; Samuels, M.H.; Sawka, A.M.; et al. An online survey of hypothyroid patients demonstrates prominent dissatisfaction. Thyroid 2018, 6, 707-721. [CrossRef] [PubMed]

57. Mitchell, A.L.; Hegedüs, L.; Žarković, M.; Hickey, J.L.; Perros, P. Patient satisfaction and quality of life in hypothyroidism: An online survey by the british thyroid foundation. Clin. Endocrinol. 2020. [CrossRef]

58. Jorgensen, P.; Langhammer, A.; Krokstad, S.; Forsmo, S. Is there an association between disease ignorance and self-rated health? The HUNT Study, a cross-sectional survey. BMJ Open 2014, 4, e004962. [CrossRef] [PubMed]

59. Yalcin, M.M.; Altinova, A.E.; Cavnar, B.; Bolayir, B.; Akturk, M.; Arslan, E.; Ozkan, C.; Cakir, N.; Toruner, F.B. Is thyroid autoimmunity itself associated with psychological well-being in euthyroid Hashimoto's thyroiditis? Endocr. J. 2017, 64, 425-429. [CrossRef]

Publisher's Note: MDPI stays neutral with regard to jurisdictional claims in published maps and institutional affiliations.

(C) 2020 by the authors. Licensee MDPI, Basel, Switzerland. This article is an open access article distributed under the terms and conditions of the Creative Commons Attribution (CC BY) license (http://creativecommons.org/licenses/by/4.0/). 